\title{
Recurrent benign adrenal pheochromocytomas associated with hemihypertrophy
}

\author{
Maria Pikilidou, ${ }^{1,3}$, Maria Yavropoulou ${ }^{2}$ and Marios Katsounaros ${ }^{3}$ \\ ${ }^{1}$ Hypertension Excellence Center, First Department of Internal Medicine ${ }^{2}$ Division of Endocrinology and \\ Metabolism, AHEPA University Hospital, Thessaloniki, Greece \\ ${ }^{3}$ Second Department of Internal Medicine, Papanikolaou General Hospital, Thessaloniki, Greece
}

Correspondence should be addressed to $M$ Yavropoulou Email margia@med.auth.gr

\section{Summary}

We report a case of a female with hemihypertrophy, who developed five recurrences of pheochromocytomas until the age of 35. Timely follow-up of the patient's blood pressure assisted in early diagnosis and treatment of recurrent tumors.

\section{Learning points:}

- Recurrent benign pheochromocytomas should raise suspicion of a genetic syndrome.

- A pheochromocytoma at a young age has a high propensity to recur and strict follow-up is mandatory.

\section{Background}

Pheochromocytomas and paragangliomas (PGLs) are catecholamine-secreting tumors of neural crest origin that arise from the adrenal medulla or extra-adrenal sympathetic paraganglia respectively. In the last decade, identification of multiple susceptibility genes has revealed an extensive genetic heterogeneity of these tumors. Catecholamine secretion is usually unpredictable, resulting in hypertension, arrhythmias, and/or hyperglycemia, and therefore tumor resection remains the gold standard of treatment (1). Although long-term postoperative remission is usually encountered in patients with benign tumors and the survival rates are similar to those of the normal population, tumor recurrence has also been reported with a frequency of between 6 and 23\% (2). The highest rate of recurrence is usually associated with familial syndromes such as multiple endocrine neoplasia type 2 (MEN2), neurofibromatosis type 1 or von Recklinghausen's disease, von Hippel-Lindau (VHL) disease, and hereditary pheochromocytoma-PGLs syndrome (3). All these syndromes are based on autosomal dominant inheritance. The first two are associated with germline mutations in tumor suppressor genes. VHL mutations, however, result in a pseudo-hypoxic state through decreased degradation of HIF (cluster 1 transcriptome) and PGLs are attributed to mutations in succinate dehydrogenase (SDH) subunit genes $S D H B, S D H C$, and $S D H D$ that comprise portions of mitochondrial complex II (4). In the last four years, four new genes namely SDHA, SDHAF2, MAX, and TMEM127 have also been found to be associated with predisposition to pheochromocytomas and PGLs (1).

Bilateral adrenal pheochromocytomas have also been described in patients with Beckwith-Wiedemann syndrome (BWS), a pediatric overgrowth disorder, usually presenting with hemihypertrophy and involving predisposition to tumor development (5) (6) (7) (8). It is caused by mutation or deletion of imprinted genes within the chromosome $11 \mathrm{p} 15.5$ region, which harbors the insulinlike growth factor 2 (IGF2) gene. Tumors associated with this syndrome are usually of embryonic origin, such as Wilms' tumor, hepatoblastomas, and neuroblastomas (4). The incidence of malignancy in such patients is irrespective of the site with a rate of $\sim 7.5 \%$ (4).

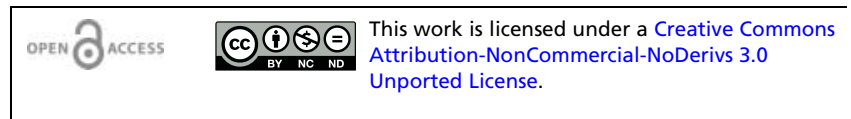




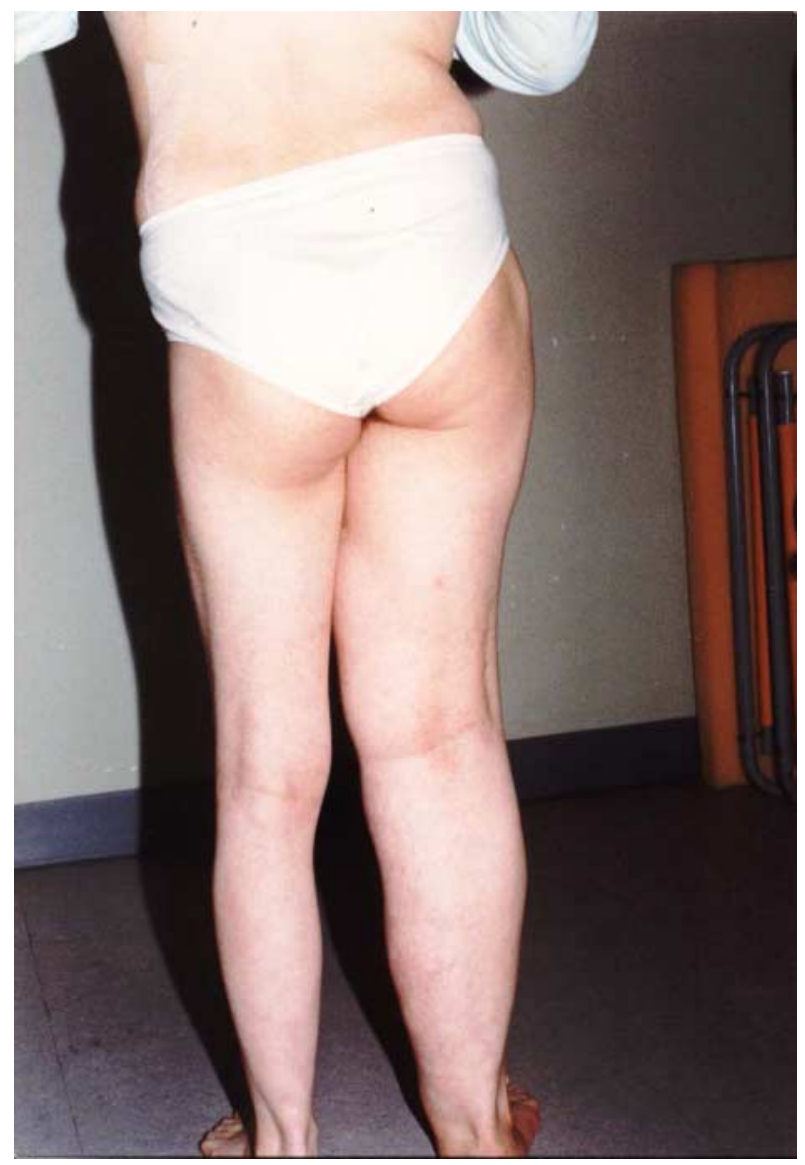

Figure 1

Patient with the right hemihypertrophy.

\section{Case presentation}

A 33-year-old woman was admitted to the outpatient clinic in 2007 referring severe headaches refractory to painkillers, episodic, and paroxysmal hypertension associated with postural changes and palpitations.

From her medical record, the patient was diagnosed with a benign hepatoma at the age of six months and was treated with right hemihepatectomy and plastic surgery of the abdominal wall. At the age of six, the patient was diagnosed with pheochromocytoma of the left adrenal gland and was submitted to subtotal adrenalectomy. Four years later at the age of ten, a new pheochromocytoma was diagnosed at the right adrenal gland and was again treated with subtotal adrenalectomy. At the age of 17 , a third pheochromocytoma was identified in the anatomic region of the left adrenal gland by meta-iodobenzylguanidine (MIBG) scintiscan and was also resected.

\section{Investigation}

During her clinical examination in our center, the patient had right ipsilateral hemihypertrophy, significant leg length discrepancy (left leg, $85 \mathrm{~cm}$ and right leg, $92 \mathrm{~cm}$ ), and abdominal wall defects (Fig. 1). At the time of admission, her blood pressure was $270 / 140 \mathrm{mmHg}$ with a heart rate of 146 b.p.m. (sinus tachycardia). Remarkable findings from the laboratory examinations included significantly elevated $24 \mathrm{~h}$ urine 3-methoxy-4-hydroxymandelic acid, and fractionated metanephrine levels and increased plasma metanephrine levels (Table 1). A new pheochromocytoma was then clinically and biochemically suspected and magnetic resonance imaging (MRI) scan of the abdomen identified a tumor on the anatomic region of the left adrenal gland (Fig. 2a).

\section{Treatment}

Soon after diagnosis, resection of the tumor was performed (Fig. 2b).

\section{Outcome and follow-up}

Histopathological analyses revealed a well-circumscribed tumor of size $4.5 \mathrm{~cm}$ and weighing $90 \mathrm{~g}$, with areas of cystic degeneration. There were no features of vascular invasion or extension into the periadrenal soft tissues and the tumor cells were arranged in the characteristic

Table 1 Laboratory examinations during our first evaluation of the patient. Values in bold are out of the normal range.

Plasma total metaneprines $(<1.04 \mathrm{nmol} / \mathrm{ml})$

$1.5 \mathrm{nmol} / \mathrm{ml}$

24 h-urine - fractionated metanephrines $1750 \mathrm{nmol} / 24 \mathrm{~h}$

(NR; $126.8-1125.6 \mathrm{nmol} / 24 \mathrm{~h}$ )

24 h-urine - VMA (NR; $1.5-6.5 \mathrm{mg} / 24 \mathrm{~h})$

Chromogranin A (NR; 0-5 nmol/l)

Aldosterone (NR; $<776 \mathrm{pmol} / \mathrm{l})$

PRA (NR; 0.12-2.7 ng/l per s)

Cortisol (NR; 171-536 nmol/l)

ACTH (NR; $1.11-6 \mathrm{pmol} / \mathrm{l})$

TSH (NR; 0.4-4.50 mU/l)

Calcitonin (basal; $<8 \mathrm{pg} / \mathrm{ml}$ )

Glucose (NR; 70-110 mg/dl)

Creatinine (NR; $0.40-1.10 \mathrm{mg} / \mathrm{dl})$

ESR (NR; 0-20 mm)

Phosphate (NR; $2.7-4.5 \mathrm{mg} / \mathrm{dl}$ )

Calcium (NR; 8.6-10.2 mg/dl)

$\mathrm{Mg}(\mathrm{N} ; 1.7-2.2 \mathrm{mg} / \mathrm{dl})$

ALP (NR; 8.4-29.3 $\mu \mathrm{g} / \mathrm{l})$

PTH (NR; $1.0-6.5$ pmol/l)

WBC (Poly:Lym:Eos)

$55.3 \mathrm{mg} / 24 \mathrm{~h}$

$17 \mathrm{nmol} / \mathrm{l}$

$350 \mathrm{pmol} / \mathrm{l}$

$1.8 \mathrm{ng} / \mathrm{l}$ per s

$314 \mathrm{nmol} / \mathrm{l}$

$3.5 \mathrm{pmol} / \mathrm{l}$

$2.2 \mathrm{mU} / \mathrm{l}$

$1.6 \mathrm{pg} / \mathrm{ml}$

$92 \mathrm{mg} / \mathrm{dl}$

$0.45 \mathrm{mg} / \mathrm{dl}$

$12 \mathrm{~mm}$

$3.2 \mathrm{mg} / \mathrm{dl}$

$9.60 \mathrm{mg} / \mathrm{dl}$

$2.0 \mathrm{mg} / \mathrm{dl}$

$18 \mu \mathrm{g} / \mathrm{l}$

$4.8 \mathrm{pmol} / \mathrm{l}$

$7.66(56: 22: 0.2)$

VMA, vanillylmandelic acid; NR, normal range. 
(a)

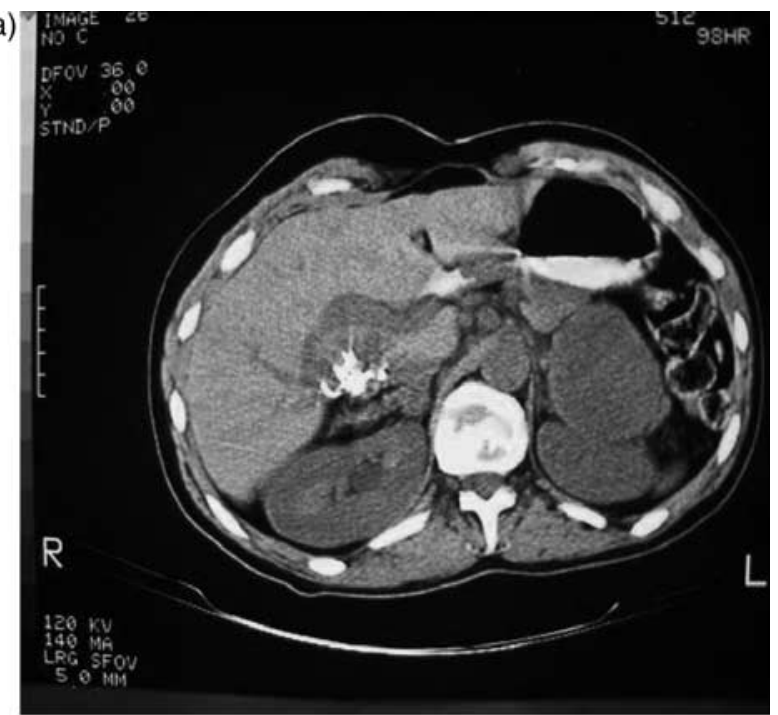

(b)

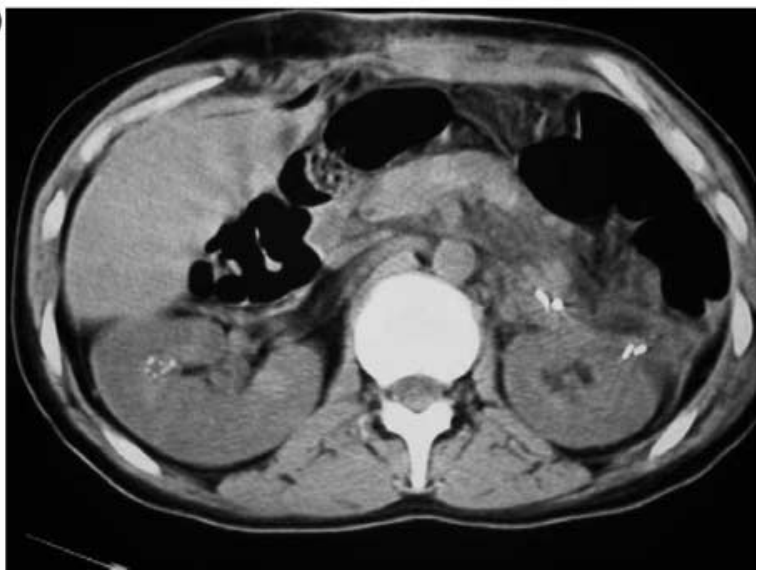

Figure 2

MRI of the abdomen showing (a) a heterogeneous mass in the anatomic region of the left adrenal gland. (b) Imaging after resection of the tumor.

'zellballen' architecture. The tumor demonstrated positive immunoreactivity for pheochromocytoma with chromogranin and synaptophysin and membrane immunoreactivity with $\mathrm{CD} 56$. The mitotic index was 0.4 mitoses per ten high power fields (HPFs) and no atypical mitotic forms were identified. The Ki-67 index was $<1 \%$.

Following surgery, her blood pressure became normalized and at the fifth postoperative day she was discharged home without antihypertensive treatment. The patient did not require replacement therapy with hydrocortisone and/or fludrocortisone. The patient had regular visits every 6 months with measurement of blood arterial pressure and urine metanephrines.

Two years later, the patient presented again to the outpatient clinic complaining for tachycardia. The $24 \mathrm{~h}$ blood pressure (BP) measurement reveals normal blood pressure and a relevant tachycardia (100 b.p.m.). In laboratory examinations, the patient had elevated $24 \mathrm{~h}$ urine metanephrine and normetanephrine levels (1840 and $1693 \mathrm{nmol} / 24 \mathrm{~h}$ respectively) and we proceeded with MRI for the localization of the tumor. The MRI revealed the presence of a heterogeneous mass with the characteristic, for pheochromocytomas, high signal intensity on T2-weighted imaging in the anatomic region above the uterus, that most probably represents a locoregional recurrence after tumor spill. The patient was reluctant to undergo further surgery and she was discharged with antihypertensive treatment ( $\alpha$ and $\beta$ blockade).

\section{Genetic analysis}

Based on her clinical appearance (hemihypertrophy and abdominal wall defects) and her medical record, the diagnosis of BWS was suspected. According to the Children's Association of New Zealand (9) (10), the diagnosis of BWS is based on clinical suspicion and presence of two of the five major characteristics, namely macroglossia, unexplained hypoglycemia in the first 4 months of life, ear creases or pits, abdominal wall defect (including minor naval hernia), and birth weight over 90-95\% (adjusted for prematurity if relevant).

However, genetic analysis did not confirm our clinical diagnosis. Multiplex ligation-dependent probe analysis revealed no epigenetic alterations in 11p15.5, which included investigation for hypomethylation at KCNQ1OT1 and hypermethylation at ICR1, and also no $11 \mathrm{p} 15.5$ uniparental disomy (UPD) was found. Karyotyping with g-banding performed in the whole blood showed 46,XX chromosomes.

\section{Discussion}

Multiple benign pheochromocytomas are rare in the general population, and the prevalence is not known. Malignant behavior is present in $10 \%$ of pheochromocytomas and currently, no absolute histomorphological, genetic, molecular, or immunohistochemical findings are available to differentiate between malignant and benign pheochromocytomas, except for the presence of distant metastases (11). Extensive local invasion and confluent tumor necrosis are 'suspicious' features.

In our case, there were no invasive tumors or any other signs of malignancy. However, due to the lack of definite criteria, the possibility of an unrecognized malignancy cannot be completely excluded. 
Hemihypertrophy is usually associated with rare genetic syndromes such as Simpson-Golabi-Behmel syndrome, Costello syndrome, Perlman syndrome, Sotos syndrome, and mucopolysaccharidosis type $\mathrm{V}$, although sporadic cases of idiopathic-isolated hemihypertrophy have also been reported (12). The latter was also characterized by genetic heterogeneity and has been referred as partial BWS (9).

BWS is a rare congenital disorder characterized by hemihypertrophy, embryonic tumors, adrenocortical cytomegaly, ear anomalies (anterior linear earlobe creases and posterior helical pits), visceromegaly, renal abnormalities, neonatal hypoglycemia, cleft palate, and a positive family history (7) (9) (13). Occurrence is usually sporadic, but familial distribution has also been reported, with an incidence of $\sim 1: 13700$ births (4).

According to the literature, five cases describing the association of the syndrome with bilateral adrenal pheochromocytomas have been reported so far (5) (14) (15) (16) (17). The first case described a 20-year-old female patient in whom BWS was diagnosed within a few days of birth from the association of hydramnios, omphalocele, right hemihypertrophy affecting the pelvis and upper and lower limbs, hepatomegaly, and episodes of hypoglycemia. The patient presented with high blood pressure and bilateral pheochromocytoma and was treated successfully with laparoscopic operation (14). In another case report, a 6-year-old boy with BWS presented with hypertension, tachycardia, and enlarged adrenal glands, and resection of the larger right adrenal gland revealed three nodular lesions histologically compatible with multifocal pheochromocytoma (5). The third report involves a girl with BWS without hypertension that was diagnosed with pheochromocytoma and had adrenalectomy at the age of 8 years. Consequently, after seven months, she developed a second pheochromocytoma that was again resected. The patient had stenosis of multiple large and medium arteries including the carotid, the renal, and the celiac artery. Her subsequent course included a right hemiplegic stroke and recurrent transient ischemic attacks (15).

The fourth case represents a very similar case to the present, involving a 19-year-old female with congenital hemihypertrophy and bilateral benign pheochromocytoma. In this patient, screening for MEN2A and MEN2B in the DNA of peripheral blood lymphocytes was negative. Screening for somatic and germline mutations in the $V H L$ and RET genes in the adrenal tumor was also negative and methylation patterns for LIT1 (KCNQ1OT1) and H19 genes associated with BWS were normal. After bilateral adrenalectomy, the patient received hormonal substitution for adrenal deficiency and yearly screening of urinary catecholamines was advised (16).

The fifth case involved early-onset bilateral pediatric pheochromocytomas caused by mosaic chromosome 11 p15 paternal UPD, which was recently reported. It involves an 18-month-old girl, who at the age of 4 months presented with bilateral pheochromocytomas (17).

Patients with BWS may exhibit other adrenal tumors as well. Alsultan et al. described a case of a 6-month-old patient with bilateral adrenal tumors and increased MIBG uptake within the left adrenal tumor. However, histology revealed a neuroblastoma on the left adrenal and an atypical adrenocortical tumor on the right (18). Similarly, Beauloye et al. presented bilateral asynchronous adrenal adenomas in a girl with an incomplete form of BWS. In this case, 24-h urinary 17-ketosteroids, as well as plasma androgens, were elevated and both tumors showed the same atypical histomorphology after resection (19).

It was found that $85 \%$ of BWS cases are karyotypically normal. The genetic background is associated, although not always diagnostic, with mutations or deletions of imprinted genes within the chromosomic region 11p15.5. Five imprinted genes have demonstrated causal relationship: IGF2, H19, cyclin-dependent kinase inhibitor $1 \mathrm{C}$ (CDKN1C), potassium voltage-gated channel, KQT-like subfamily, member 1 (KCNQ1), and KCNQ1 overlapping transcript 1 (KCNQ1OT1). The only mutations within a gene are loss-of-function mutations in the CDKN1C gene, which encodes for a cell cycle regulator (20). CDKN1C mutations appear to be particularly associated with umbilical abnormalities, but not with increased predisposition to Wilms' tumor. Epigenetic factors have also been reported including UPD of 11p15, hypomethylation of KCNQ1OT1 gene, and hypermethylation of the genes H19, LIT1, and IGF2 (20).

Tested epigenetic alterations were not indicative of BWS in our patient. However, epigenetic alterations may be supportive to the clinical diagnosis but cannot definitively exclude the syndrome. There may be a wide heterogeneity for epimutations regarding BWS, as the causative genetic factors are still unknown.

Our patient is a rare case presenting with multiple recurrent benign pheochromocytomas associated with hemihypertrophy. Although we were not able to reach a definite diagnosis with genetic confirmation, a partial BWS with idiopathic hemihypertrophy (BWS/HH) seems to be the most plausible diagnosis. Other syndromes that are associated with hemihypertrophy usually have distinctive facial or cerebral features and mental retardation, which was not the case for our patient. 
Cases of benign recurrent pheochromocytomas can be part of rare congenital syndromes and further genetic research is warranted in order to identify novel disease genes and shed light into complex clinical cases that remain undiagnosed. Timely follow-up of the patient's blood pressure and resection of the tumor when able to localize remain the gold standard in the therapeutic approach of these patients.

\section{Declaration of interest}

The authors declare that there is no conflict of interest that could be perceived as prejudicing the impartiality of the research reported.

\section{Funding}

This research did not receive any specific grant from any funding agency in the public, commercial or not-for-profit sector.

\section{Patient consent}

Written informed consent of the patient was obtained.

\section{Author contribution statement}

Drs M Pikilidou and M Katsounaros were the physicians who treated the patient. Dr M Yavropoulou was the consulting endocrinologist. All authors contributed to the writing of the manuscript.

\section{References}

1 Lefebvre M \& Foulkes WD 2014 Pheochromocytoma and paraganglioma syndromes: genetics and management update. Current Oncology 21 e8-e17. (doi:10.3747/co.21.1579)

2 Amar L, Servais A, Gimenez-Roqueplo AP, Zinzindohoue F, Chatellier G \& Plouin PF 2005 Year of diagnosis, features at presentation, and risk of recurrence in patients with pheochromocytoma or secreting paraganglioma. Journal of Clinical Endocrinology and Metabolism 90 2110-2116. (doi:10.1210/jc.2004-1398)

3 Young WF \& Kaplan NM. Pheochromocytoma in genetic disorders (http://www.uptodate.com/contents/pheochromocytoma-in-geneticdisorders), 2013.

4 Mannens M, Alders M, Redeker B, Bliek J, Steenman M, Wiesmeyer C, de Meulemeester M, Ryan A, Kalikin L, Voute T et al 1996 Positional cloning of genes involved in the Beckwith-Wiedemann syndrome, hemihypertrophy, and associated childhood tumors. Medical and Pediatric Oncology 27 490-494. (doi:10.1002/(SICI)1096-

911X(199611)27:5 < 490::AID-MPO17> 3.0.CO;2-E)

5 Baldisserotto M, Peletti AB, Angelo de Araujo M, Pertence AP, Dora MD, Maciel EO \& Gaiger AM 2005 Beckwith-Wiedemann syndrome and bilateral adrenal pheochromocytoma: sonography and MRI findings. Pediatric Radiology 35 1132-1134. (doi:10.1007/s00247005-1518-3)
6 Beckwith JB 1969 Macroglossia, omphalocele, adrenal cytomegaly, gigantism and hyperplastic visceromegaly. Birth Defects Original Article Series 2 188-196.

7 Weng EY, Moeschler JB \& Graham JM, Jr 1995 Longitudinal observations on 15 children with Wiedemann-Beckwith syndrome. American Journal of Medical Genetics 56 366-373. (doi:10.1002/ajmg. 1320560405)

8 Wiedemann HR 1964 Complexe malformatif familial avec hernie ombilicale et macroglossie - un 'syndrome nouveau'? Journal de Génétique Humaine 13 223-232.

9 Elliott M, Bayly R, Cole T, Temple IK \& Maher ER 1994 Clinical features and natural history of Beckwith-Wiedemann syndrome: presentation of 74 new cases. Clinical Genetics 46 168-174. (doi:10.1111/j.1399-0004. 1994.tb04219.x)

10 Gomes MV \& Ramos ES 2003 Beckwith-Wiedemann syndrome and isolated hemihyperplasia. São Paulo Medical Journal 121 133-138. (doi:10.1590/S1516-31802003000300010)

11 Plouin PF, Fitzgerald P, Rich T, Ayala-Ramirez M, Perrier ND, Baudin E \& Jimenez C 2012 Metastatic pheochromocytoma and paraganglioma: focus on therapeutics. Hormone and Metabolic Research 44 390-399. (doi:10.1055/s-0031-1299707)

12 Hoyme HE, Seaver LH, Jones KL, Procopio F, Crooks W \& Feingold M 1998 Isolated hemihyperplasia (hemihypertrophy): report of a prospective multicenter study of the incidence of neoplasia and review. American Journal of Medical Genetics 79 274-278. (doi:10.1002/ (SICI)1096-8628(19981002)79:4 < 274::AID-AJMG8 > 3.0.CO;2-M)

13 Pettenati MJ, Haines JL, Higgins RR, Wappner RS, Palmer CG \& Weaver DD 1986 Wiedemann-Beckwith syndrome: presentation of clinical and cytogenetic data on 22 new cases and review of the literature. Human Genetics 74 143-154. (doi:10.1007/BF00282078)

14 Bemurat L, Gosse P, Ballanger P, Tauzin-Fin P, Barat P, Lacombe D, Lemetayer P \& Clementy J 2002 Successful laparoscopic operation of bilateral pheochromocytoma in a patient with Beckwith-Wiedemann syndrome. Journal of Human Hypertension 16 281-284. (doi:10.1038/ sj.jhh.1001378)

15 Wilson M, Peters G, Bennetts B, McGillivray G, Wu ZH, Poon C \& Algar E 2008 The clinical phenotype of mosaicism for genome-wide paternal uniparental disomy: two new reports. American Journal of Medical Genetics. Part A 146A 137-148. (doi:10.1002/ajmg.a.32172)

16 van den Akker EL, de Krijger RR, de Herder WW \& Drop SL 2002 Congenital hemihypertrophy and pheochromocytoma, not a coincidental combination? European Journal of Pediatrics 161 157-160. (doi:10.1007/s00431-001-0901-9)

17 Kalish JM, Conlin LK, Mostoufi-Moab S, Wilkens AB, Mulchandani S, Zelley K, Kowalski M, Bhatti TR, Russo P, Mattei P et al 2013 Bilateral pheochromocytomas, hemihyperplasia, and subtle somatic mosaicism: the importance of detecting low-level uniparental disomy. American Journal of Medical Genetics. Part A 161A 993-1001. (doi:10.1002/ajmg. a.35831)

18 Alsultan A, Lovell MA, Hayes KL, Allshouse MJ \& Garrington TP 2008 Simultaneous occurrence of right adrenocortical tumor and left adrenal neuroblastoma in an infant with Beckwith-Wiedemann syndrome. Pediatric Blood \& Cancer 51 695-698. (doi:10.1002/pbc.21694)

19 Beauloye V, Zain F, Malvaux P, Rahier J, Gosseye S, Honour JW \& Maes M 2001 Bilateral asynchronous adrenal adenoma in a girl with an incomplete form of Beckwith-Wiedemann syndrome. European Journal of Pediatrics 160 142-143. (doi:10.1007/s004310000653)

20 Enklaar T, Zabel BU \& Prawitt D 2006 Beckwith-Wiedemann syndrome: multiple molecular mechanisms. Expert Reviews in Molecular Medicine $\mathbf{8}$ 1-19. (doi:10.1017/S1462399406000020)

Received in final form 19 June 2014

Accepted 3 July 2014 